\title{
Health and Social Conditions of Older People in Albania: Baseline Data from a National Survey
}

\author{
Alban Ylli MD, MSc, $\mathrm{PhD}^{1}$
}

\begin{abstract}
The paper presents the data from a household survey in a representative sample of the population of individuals over 65 years old in three regions of Albania. The survey included a quantitative assessment of socioeconomic situation including poverty, social participation and social exclusion, as well as assessment of ill-health including limitations of daily living activities and chronic conditions.

It was found that older people in urban areas are better covered with social security as compared to older residents in rural and informal areas. One third (32\%) of participants reported not good or bad health and the majority (57\%) of them were poor or very poor. Significant differences were found with individuals residing in informal areas around Tirana, reporting worse health conditions than elderly people living in urban areas. Approximately one fifth $(18 \%)$ were totally or partially isolated from social networks. Prevalence of selected chronic conditions ranged from 9 percent to 58 percent. Almost the totality (93\%) of the sample experienced some pain and 9 percent were bed-bound. More than one in four $(27 \%)$ reported not receiving medical care when they needed it.

Demographic trends mixed with a society in economic and political transition raise concerns about increasing needs for care and social inclusion of older people. Moreover, there is a low level of preparation of this society to cope with chronic diseases and long-term care. The findings suggest specific policies and actions to be considered by a number of stakeholders, including government and civic society.
\end{abstract}

Key Words: Eastern Europe, aging, older adults, demographics

Recommended Citation: Ylli A. Health and Social Conditions of Older People in Albania: Baseline Data from a National Survey. Public Health Reviews. 2010;32:549-60.

\footnotetext{
${ }^{1}$ Faculty of Medicine, University of Tirana, Institute of Public Health, General Secretary, Albanian Association of Geriatry, Gerontology.
}

Corresponding Author Contact Information: Alban Ylli at albanylli@yahoo.co.uk; Faculty of Medicine, University of Tirana, Institute of Public Health, General Secretary, Albanian Association of Geriatry, Gerontology, Albania. 


\section{BACKGROUND}

\section{Similarities with other countries in the region}

As in all European societies, "young" elderly people in Albania (60-70 year olds) are expected to carry out a set of demanding social responsibilities for which the utmost emotional and physical fitness is required. However, this age group faces many challenges related to the fast pace of socioeconomic transition, similar to the situation in other countries of Southeast Europe. As in those countries, Albania is a gradually ageing society and this trend will continue. Nevertheless, it must be pointed out that information on the social situation and health status of elderly people in Albania has been scarce until now, and this study represents the first real attempt to assess the situation of older people in Albania.

A common trend in all countries of Southeast Europe is a declining birth rate and emigration of young people, which is causing a substantial increase in the share of the population over 65 years of age. ${ }^{1}$ This situation is particularly evident in Albania, Kosovo and Macedonia. Throughout the region, the population most at risk of ill health are older people living alone and those living in rural areas. In Serbia, for example, four out of five individuals aged over 70 years have chronic diseases. ${ }^{2}$ However, the elderly are inadequately informed of the availability of support services intended for them. Worse yet, the poorest elderly are the least informed of such services. A substantial number of elderly people need help to conduct their normal daily living activities both inside and outside of the home. Yet, only 9 percent of Serbians aged 70 years take advantage of support services available to this age group. Moreover, it has been pointed out that elderly people in Southeast Europe are also at risk from abuse both in institutions and at home. ${ }^{1}$ Despite these concerns, systematic data on the socioeconomic situation and health status of elderly people are scant for most countries of the region.

\section{Demographic transition}

According to the information provided by the INSTAT reports between 1991 and 2008, the proportion of the population over 65 years of age in Albania rose from 3.2 percent to 10.4 percent and the official projections indicate that it should reach 12.2 percent by this year, 2010 (INSTAT, the most recent census was carried out during 2001). A 1993 estimate projected that the proportion of older people would double over the next 35 years. ${ }^{3}$ Coupled with falling birth rates and increasing life expectancy, this will eventually lead to a substantial reduction of the economically active proportion of the population. At the same time, high levels of chronic 
illness, a huge burden of avoidable disability, economic deprivation and a lack of social opportunities mean that most elderly people in Albania are in a struggle to survive rather than enjoying the personal and social possibilities common in many other European countries. Consequently, the Albanian society as a whole is deprived of much of the contribution it could gain from the experience of its older citizens.

\section{Socioeconomic situation}

Elderly people in Albania face many socioeconomic problems that have been exacerbated by the rapid transition from a centralised system towards a market-oriented economy, which is associated with serious difficulties and challenges for this vulnerable segment of the population. Unjustifiably, reports of the National Institute of Statistics claim that elderly people are not the most socioeconomic disadvantaged age group of the population, which poses serious difficulties for the work carried out by the institutions, agencies, civil society and non-governmental associations (NGOs) working with elderly people in Albania. It must be noted, however, that there are no systematic official data about the prevalence of poverty among elderly people in Albania.

\section{Existing data on health status}

The data on health status of Albanian elderly are very scarce. Existing information is not published and based on intervention projects. According to a survey conducted by the Albanian Association of Geriatrics and Gerontology in 1999, two thirds of elderly people enrolled in Tirana Primary care services suffered from at least one chronic disease (including hypertension), whilst nearly one third suffered from two or more chronic conditions. The most frequent chronic diseases were cardiovascular disease (CVD), diabetes and arthritis. Another programme promoting screening for health conditions among elderly, conducted in 2003 in Kruja (a small district in central Albania) reported a slightly lower prevalence of elderly suffering from at least one chronic condition (62\%), but a higher rate of social isolation and poverty.

Based on some findings reported by the Institute of Public Opinion Studies (an NGO), about 43 percent of elderly people (aged 65 years and over) in Tirana in 2004 sought medical care in primary healthcare facilities referred to as polyclinics, whereas 45 percent were unable to seek medical care despite being in need of such services. Conversely, about 12 percent of elderly reported not seeking medical care in the past few years because their health status was satisfactory. 


\section{The aim of the survey}

A national survey was conducted from November 2007 - July 2008 by the Albanian Association of Geriatry and Gerontology to provide valid data on the condition of older people in Albania. Collaboration in the form of technical expertise and financial assistance was provided from Help the Aged.

This paper presents data on health status (chronic conditions, disability, limitations of daily living activities) and health needs of elderly people including availability, accessibility and affordability of healthcare services. Other data include socioeconomic conditions of elderly people: amenities, poverty rate; as well as social participation/social exclusion and the sense of autonomy/dependence.

These data produced by a valid methodology may represent a unique source for further international comparisons as well as a national baseline for Albania.

\section{METHODS}

The target population of the survey were all persons over 65 years old, living in three main districts of Albania; Tirana - the Albanian capital; Shkoder - the main district in north Albania, and; Vlora - the main district in south Albania. Their total population makes up almost half of the Albanian Population. These districts were chosen so that the overall sample was representative of the older population of Albania as a whole. A representative multi-stage cluster sample of the elderly population of these areas was selected. The sample was stratified by place of residence: rural vs. urban areas.

The sampling frame in Tirana city consisted of the population lists according to the residential distribution in 11 administrative units (referred to as mini-municipalities which we stratified into higher-, middle- and lowerincome groups based on information available from the National Institute of Statistics). Out of 11 mini-municipalities, three mini-municipalities (one higher-income, one middle-income and one lower-income) were randomly selected at the first stage. Next, each mini-municipality was divided into a number of blocks; subsequently, two blocks were randomly selected from each of the three mini-municipalities. Furthermore, one slum neighborhood and three villages were selected at random in the Tirana district and in Shkoder and Vlora districts. The sampling in these regions consisted of the selection of a random neighborhood in an urban area and a random rural village.

Finally, all elderly people (individuals aged 65 years and older) residing in the randomly selected neighborhoods and villages were invited for an 
interview. The potential participants received an explanation of the aim and objectives of the study and those who agreed to participate in the survey were subsequently interviewed.

The study employed a structured questionnaire. The interviews were conducted face to face in selected households by 12 trained interviewers. The average time to complete an interview was approximately 20 minutes. The survey achieved a response rate of 91 percent and virtually no one refused to take part in the interviewing process after being contacted.

Data entry and editing for the quantitative component of the survey was performed in Excel. Data analysis was conducted in SPSS (Statistical Package for Social Sciences, version 15.0, Chicago, IL).

\section{RESULTS}

\section{Demographic characteristics of the study population}

The numbers of elderly people included in the survey by district and place of residence (urban vs. rural area) are presented in Table 1:

Table 1

Number of study participants by district and place of residence

\begin{tabular}{c|c|c|c|c|c|c|c|c|c|c|c|c}
\hline & \multicolumn{3}{|c|}{ Tirana } & \multicolumn{3}{c|}{ Shkodra } & \multicolumn{3}{c|}{ Vlora } & \multicolumn{3}{c}{ Overall } \\
\cline { 2 - 13 } & Men & Women & Total & Men & Women & Total & Men & Women & Total & Men & Women & Total \\
\hline $\begin{array}{c}\text { Rural } \\
\text { areas }\end{array}$ & 58 & 54 & 112 & 78 & 56 & 134 & 41 & 53 & 94 & 177 & 163 & 340 \\
\hline $\begin{array}{c}\text { Informal } \\
\text { areas* }\end{array}$ & 50 & 44 & 94 & - & - & - & - & - & - & 50 & 44 & 94 \\
\hline $\begin{array}{c}\text { Urban } \\
\text { areas }\end{array}$ & 129 & 102 & 231 & 50 & 80 & 130 & 69 & 49 & 118 & 248 & 231 & 479 \\
\hline Total & 237 & 200 & 437 & 128 & 136 & 264 & 110 & 102 & 212 & 475 & 438 & 913 \\
\hline
\end{tabular}

* Informal areas are urban neighbourhoods in Tirana city that consist of internal migrants mostly from poorer districts of north and northeast Albania.

Overall, $475(52 \%)$ men and $438(48 \%)$ women were included in the survey. The sex distribution was more or less similar in all three districts, with 45.8 percent female participants in Tirana, 51.5 percent in Shkodra, and 48.1 percent in Vlora. It was also similar in terms of place of residence, with 47.9 percent female participants in rural areas, 46.8 percent in informal areas in Tirana, and 48.2 percent in urban areas. 
The overall mean age of participants was $73.21 \pm 6.39$ years; it was $72.98 \pm 6.52$ years in Tirana, $73.28 \pm 7.01$ years in Shkodra, and $73.61 \pm$ 5.21 years in Vlora. On average, participants from rural areas were slightly younger than individuals from urban areas (71.88 years vs. 74.18 years).

In age distribution, 36.8 percent of participants were "very old" (aged 75 years and over) as compared to 63.2 percent of individuals aged less than 75 years. The age distribution of elderly people was similar in all three districts included in the survey. The proportion of the very old included in the study, however, was higher in urban areas compared with rural areas ( $43.4 \%$ vs. $28.8 \%)$

The mean number of family members was $2.54 \pm 2.31$; it was slightly higher in rural areas $(2.74 \pm 2.26)$ compared with urban areas $(2.40 \pm 2.28)$, and in men compared to women (about 3 family members in men vs. 2 in women). The later finding was in line with a higher rate of widowed, divorced and/or single females (53.9\%) as opposed to males (24.4\%).

\section{Economic conditions}

Overall, 766 (84\%) of participants had running water in their homes/ apartments. There were, however, huge differences between areas: there was running water in 99.8 percent of urban areas as opposed to only 72.3 percent in informal areas of Tirana and 65 percent in rural areas in all three districts.

The same unequal distribution was evident for availability of a bathroom or WC inside the house/apartment, with 100 percent in urban areas as compared to 66.0 percent in informal areas and 64.7 percent in rural areas. Overall, electricity was available in 93.6 percent of houses/apartments $(99.2 \%$ in urban areas, $87.2 \%$ in informal areas of Tirana and $87.6 \%$ in rural areas) notwithstanding the frequent power cuts, especially in rural areas. Only 72.6 percent of participants reported having adequate heating in their homes (77.2\% in urban areas, $74.5 \%$ in informal areas, and $65.6 \%$ in rural areas).

Overall, 78.0 percent of participants reported having a refrigerator (87.7\% in urban areas, $67.0 \%$ in informal areas, and $67.4 \%$ in rural areas), and 89.1 percent having a TV set $(90.2 \%$ in urban areas, $90.4 \%$ in informal areas, and $87.3 \%$ in rural areas).

\section{Health status of elderly people}

Overall, 90 participants (9.9\%) assessed their health as "bad" and 202 $(22.1 \%)$ as "not good" compared to $35(3.8 \%)$ and $230(25.2 \%)$ who reported a "very good" or "good" health status, respectively. There were significant differences by place of residence with individuals residing in informal areas in Tirana reporting a far worse health condition than elderly 
people living in urban or rural areas $(18.1 \%$ vs. $6.8 \%, \mathrm{P}=0.037)$ (Table 2$)$. Notwithstanding the standardized questionnaire employed and the training of the interviewers, the observed differences in the self-perceived rates of "bad" health could also relate to differential reporting in different residential areas (i.e., in rural areas, informal and urban areas, respectively). On the other hand, there were no significant differences in self-reported chronic conditions by place of residence (Table 3 ).

Table 2

Self-assessed own health by place of residence

\begin{tabular}{l|c|c|c|c}
\hline \multicolumn{1}{c|}{ Residence } & Rural & Informal & Urban & Total \\
\hline Very Good & $5.0 \%(17)$ & $5.3 \%(5)$ & $2.7 \%(13)$ & $3.8 \%(35)$ \\
Good & $27.6 \%(94)$ & $20.2 \%(19)$ & $24.4 \%(117)$ & $25.2 \%(230)$ \\
Fair & $40.0 \%(136)$ & $34.0 \%(32)$ & $39.3 \%(188)$ & $39.0 \%(256)$ \\
Not Good & $20.6 \%(70)$ & $22.3 \%(21)$ & $23.2 \%(111)$ & $22.1 \%(202)$ \\
Bad & $6.8 \%(23)$ & $18.1 \%(17)$ & $10.4 \%(50)$ & $9.9 \%(90)$ \\
Total & $100.0 \%(340)$ & $100.0 \%(94)$ & $100.0 \%(479)$ & $100.0 \%(913)$ \\
\hline
\end{tabular}

Table 3

Self-reported chronic diseases by place of residence

\begin{tabular}{l|c|c|c|c}
\hline \multicolumn{1}{c|}{ Residence } & Rural & Informal & Urban & Total \\
\hline Yes & $77.1 \%(262)$ & $79.8 \%(75)$ & $77.0 \%(369)$ & $77.3 \%(706)$ \\
No & $22.9 \%(78)$ & $20.2 \%(19)$ & $23.0 \%(110)$ & $22.7 \%(207)$ \\
Total & $100.0 \%(340)$ & $100.0 \%(94)$ & $100.0 \%(479)$ & $100.0 \%(913)$ \\
\hline
\end{tabular}

The most prevalent own and/or spouse's chronic condition reported by participants was CVD (Table 4). The prevalence of own and spouse's selfreported diabetes was 18.7 percent and 19.5 percent, respectively (Table 4). The prevalence of the other own chronic diseases is presented in Table 5:

\section{Table 4}

Prevalence of cardiovascular disease

\begin{tabular}{l|c|c}
\hline \multicolumn{1}{c|}{ Condition } & Own $(\mathbf{9 5 \%}$ CI) & Spouse (95\% CI) \\
\hline CVD & $57.9 \%(54.7-61.2)$ & $42.5 \%(39.3-45.8)$ \\
Diabetes & $18.7 \%(16.3-21.4)$ & $19.5 \%(17.0-22.2)$ \\
\hline
\end{tabular}


Table 5

Prevalence of other chronic conditions (Own)

\begin{tabular}{l|c}
\hline \multicolumn{1}{c|}{ Condition } & Prevalence (95\% CI) \\
\hline Gastro-hepatology & $12.2 \%(10.1-14.5)$ \\
Lung diseases & $8.7 \%(6.9-10.7)$ \\
Sight problems & $30.7 \%(27.7-33.8)$ \\
Hearing impairment & $18.0 \%(15.5-20.6)$ \\
Other & $15.2 \%(13.0-17.8)$ \\
\hline
\end{tabular}

Regardless of self-reported chronic conditions, the overwhelming majority of the participants were experiencing some pain. Only a tiny minority reported being free from pain, while 141 participants $(15.4 \%)$ reported severe pain (Table 6).

Table 6

Level of self-reported pain

\begin{tabular}{l|c}
\hline \multicolumn{1}{c|}{ Level of self reported pain } & Prevalence (95\% CI) \\
\hline No pain & $6.6 \%(5.1-8.4)$ \\
Mild to moderate pain & $78.0 \%(75.2-80.6)$ \\
Severe pain & $15.4 \%(13.2-18.0)$ \\
\hline
\end{tabular}

Relating to the indicators of self-sufficiency and the need for continuous care, the data showed that 8.5 percent $(95 \% \mathrm{CI}=6.8-10.6)$ of participants themselves and 7.6 percent $(95 \% \mathrm{CI}=5.9-9.5)$ of their spouses were bedbound.

A total of 243 participants $(26.6 \%, 95 \% \mathrm{CI}=23.8-29.6)$ reported not to receive medical care when they needed it. Among the main reasons for this were difficulties to afford medical treatment $(20.5 \%, 95 \% \mathrm{CI}=17.9-23.3)$ and, to a lesser degree, the distance to healthcare facilities $(3.7 \%, 95 \%$ $\mathrm{CI}=2.6-5.2)$ and a particularly strong disease severity, which prevented participants from being able to go to the doctor $(2.7 \%, 95 \% \mathrm{CI}=1.8-4.0)$.

Conversely, the majority of elderly people $(68.9 \%, 95 \% \mathrm{CI}=65.8-71.9)$ included in the survey reported that they were not able to obtain effective medicines prescribed by their family physicians, the main reason being that they could not afford drugs. Therefore, most of the time, elderly people opted for less effective drugs which are included in the reimbursement list. 
This is, however, done at the cost of reduced effectiveness and further progression of chronic diseases.

\section{Evidence of poverty and social isolation of elderly people}

The absolute majority of elderly people residing in urban areas (99.2\%) received monthly pensions as compared to only 67 percent in informal areas in Tirana and 65.6 percent in rural areas $(\mathrm{P}<0.001)$.

A substantial percentage of participants $(66.2 \%, 95 \% \mathrm{CI}=63.0 \%$ $69.2 \%$ ) however, reported that they receive financial support (money) from their close family members or other sources such as renting an apartment (11.8\%, 95\% CI=9.8\%-14.1\%). Conversely, 4.8 percent (95\% CI=3.5\%$6.4 \%$ ) of elderly people included in the survey reported that they were employed and, therefore, received a salary.

As for perceived poverty, 16.8 percent (95\% CI=14.4\%-19.3\%) of elderly people perceived themselves as "very poor" and $40.3 \%(95 \%$ $\mathrm{CI}=37.1 \%-43.6 \%)$ as "poor" compared with only 1.9 percent $(95 \%$ $\mathrm{CI}=1.1 \%-3.0 \%$ ) who perceived themselves as "wealthy". There were significant differences by place of residence and age group with the "very olds" and those living in rural areas and informal areas displaying higher rates of self-perceived poverty (both $\mathrm{P}<0.01$ ). Regardless of the high levels of perceived poverty, only about 7 percent $(95 \% \mathrm{CI}=5.4 \%-8.9 \%)$ of participants reported having any kind of debt.

As for social contacts, a particular concern highlighted by our survey relates to the finding of 28 elderly participants $(3.1 \%, 95$ percent $\mathrm{CI}=2.1 \%$ $4.4 \%$ ) who were totally isolated and did not have any contacts at all with family members, other relatives, or friends. Moreover, the rate of almost isolated individuals (elderly people who were only occasionally visited by their children, relatives, or friends) was over 15 percent (95\% CI=12.7\%$17.5 \%)$.

More than half of the elderly people $(53.8 \%, 95 \%$ CI $=50.5 \%-57.1 \%)$ included in the survey reported that they had different problems (referred to as stressful life events) in the past 12 months (e.g., death of child(ren)/close relative/friend, divorce, separation or break-up of an intimate relationship, problems with children/close relatives/neighbours, or a serious accident/ injury at home or outside). 


\section{DISCUSSION}

Similarly to other countries, the percentage of the elderly people in Albania is growing and the rising trend will continue unabated in the years to come. ${ }^{4}$ This pattern of demographic transition has important implications for social services and the health sector in Albania, which to date is unprepared to properly face the increasing challenges related to the third age.

The socioeconomic status of elderly people in Albania is quite poor. While the overall national economy in Albania is growing, current national programmes, strategies and macro-policies do not sufficiently and adequately address the socioeconomic challenges related to elderly people in Albania. Findings from the quantitative component of the current study point out that about 57 percent of elderly people perceive themselves as poor and/or very poor. This exceeds two to three times the national average proportion of people living in poverty. ${ }^{5}$

Self-reported health is much worse compared with people under 50 years old; Only 29 percent of people included in our sample reported their health to be good or very good. Thirty-nine percent among them reported it as fair and the other 32 percent as not good or bad. When compared with the results of Albanian Demographic Health Survey, 86.6 percent of men in their early 40s consider their health as good or very good and only 2.6 percent report not good or bad health (fair - 10.8\%). The proportions do not change significantly for men in their late 40s. Women aged 40-49 have slightly higher proportions of self-perceived not good to bad health $(3.3 \%)$. It is therefore evident that self-perceived health deteriorates exponentially among the elderly with an almost ten times higher reporting of poor health among this age group than among middleaged people. ${ }^{6}$

Elderly people in Albania face huge problems and difficulties in terms of accessibility and affordability of healthcare services including medications which are necessary for the treatment of several chronic conditions (such as CVD, diabetes, gastrointestinal diseases, arthritis, etc.). Long distances to health centres, poor quality of roads, and the lack of public transport are all major obstacles to accessibility of healthcare services in rural areas of Albania. Moreover, the lack of proper reform in the healthcare sector is associated with unaffordable healthcare services (including medications) in both urban and rural areas, which primarily affects the very poor segments of society and with elderly people being particularly vulnerable due to the high demand for medical treatment in this age group.

It must be noted however, that due to continuing strong family ties many elderly people are visited by their children or other family members. 
In addition, many participants reported to be visited by and/or to pay visits to their siblings. Family networks appear to be an important asset in the Albanian society during this rapid transitional phase where the social and community networks have been disrupted.

Social participation of elderly people in Albania is particularly low and raises serious concerns. Few organized efforts and initiatives are undertaken at the community level to increase and enhance social inclusion and social participation of elderly people. National programmes dealing with third age issues undertaken by various institutions and agencies have failed so far to sufficiently involve elderly people themselves. At an individual and family level, it is quite obvious that the demographic transition coupled with the massive emigration of youth and adults to western countries is associated with increasing rates of social isolation among elderly people in Albania. It was uncommon during the communist regime for elderly people to live alone. The data from the present survey suggest that nowadays, the rate of elderly people living alone (referred to as single-member families) is rapidly increasing and this trend is consistent in all three districts included in the survey. It makes full sense to generalize that this trend is also evident in the other districts of Albania not included in the survey. Nevertheless, social services and healthcare services are unprepared to deal with this added burden due to the delay in implementation of proper activities and programmes targeting elderly people in Albania. The growing pattern of the socially isolated is also reflected in the increasing rates of stressful life events among the elderly who, among other things, tend also to report isolation from their children (due to emigration abroad, internal migration, or due to the fast pace of transition which is a serious obstacle barring children and grandchildren from interacting with elderly people on a regular basis).

Based on the findings from the current research work, some policy related recommendations might be formulated for stakeholders with influence regarding ageing issues. These recommendations may be found to be relevant as well for other countries with similar social and political backgrounds. There is a role to play for National bodies such as parliament, political parties and central government to define appropriate legislation concerning elderly social and health protection. The central government, in addition, should address more rationally and should pay more attention to the socioeconomic needs of elderly people in Albania. From this point of view, in these times of global crisis and widespread austerity measures, the government must make careful budgetary plans for the coming years, 
foreseeing a solid and larger share set aside for individuals aged 65 years and older.

The Ministry of Social Affairs is of particular importance as long as it is the immediate institution in charge of providing social care and social welfare for elderly people in Albania. It should provide leadership in implementing the recently approved strategy for ageing. Local government is another key player in this field and in the process of decentralization may take over more responsibility in providing a range of services for elderly, including identification and support for isolated and non self-sufficient older people. Finally, there is a crucial role for civic society and specialized NGOs in both filling the gaps in care and closely monitoring government in policy implementation.

\section{Acronyms list:}

$\mathrm{NGO}=$ Non-Governmental Organization

Acknowledgements: : I would like to acknowledge the support received by Dr. Reshat Koci of the Albanian Association of Geriatry and Gerontology, Dr. Genc Burazeri, Dr. Ervin Toci, Dr. Genta Qirjako at the Department of Public Health at the Faculty of Medicine in Tirana, as well as many young and old members of the MOSHA network in Tirana and districts

Conflicts of Interest: None declared.

\section{REFERENCES}

1. Doyle Y, McKee M, Rechel B, Grundy E. Meeting the challenge of population ageing. BMJ. 2009;339:b3926.

2. Sataric N, Rasevic M. The elderly nonresidential care in Serbia. A gap between needs and opportunities. Belgrade: Amity; 2007.

3. Velkoff VA, Kinsella K. Aging in Eastern Europe and the former Soviet Union. Washington (DC): U.S. Government Printing Office; 1993.

4. The World Bank. From red to gray, The "Third Transition" of aging populations in Eastern Europe and the former Soviet Union. Washington (DC): The World Bank; 2007.

5. Institute of Statistics of Albania. Albania living standards measurement survey. INSTAT; 2005.

6. Institute of Public Health, Institute of Statistics of Albania. Albanian demographic and health survey. Institute of Public Health, INSTAT, MACRO International; 2009. 